DOI: $10.31249 / \mathrm{rsm} / 2019.03 .09$

\title{
Н.А. Коровникова
}

\section{АКСИОЛОГИЧЕСКИЕ ФАКТОРЫ РЕГИОНААЬНОГО РАЗВИТИЯ СОВРЕМЕННОЙ РОССИИ}

Аннотация. В статье рассматриваются аксиологические факторы регионального развития с точки зрения их влияния на обеспечение устойчивого роста, конкурентоспособности, безопасности и интеграции регионов России.

Отмечается, что аксиологические факторы охватывают все составляюшие ментального пространства региона, в том числе "региональный культурный капитал», «региональную культуру», «региональную идентичность» и «региональный бренд». Под «культурным капиталом» понимается совокупность моральнонравственных и духовно-культурных характеристик населения региона, сформированных в контексте «региональной культуры», которая отражает основы государственной региональной политики, определяет региональную систему иенностей, способы и характер жизнедеятельности конкретной территории. В свою очередь «региональная идентичность» представляет собой результат формирования самосознания регионального сообщества как самостоятельного и самобытного субъекта, с одной стороны, и как части целостной государственной системы - с другой. Воплощением идентификационных процессов на региональном уровне является "региональный бренд», который служит публичным индикатором культурного пространства региона, а также выполняет функции выражения и удовлетворения региональных интересов и иенностей.

Показано, что аксиологические факторы могут быть реализованы в форме человекоориентированной парадигмы регионального развития, которая предполагает инклюзивные модели роста и высокие социально-экономические показатели региона. Обосновывается актуальность человекоориентированного подхода как в рамках современных теоретико-методологических исследований, так и при разработке нормативно-правовой базы регионального развития. В частности, основы человекоориентированной парадигмы отражены в Концепции долгосрочного сочииальноэкономического развития Российской Федераџии на период до 2020 г., в Основах государственной политики регионального развития Российской Федерации на период до 2025 г., а также в Стратегии государственной культурной политики на период do 2030 2.

Ключевые слова: региональное развитие; аксиологические факторы; культурный капитал региона; региональная культура; региональная идентичность; региональный бренд; человекоориентированная парадигма; Россия. 




\section{N.A. Korovnikova. Axiological Factors of Regional Development in Modern Russia}

Abstract. The article considers the axiological factors of regional development in terms of their impact on ensuring sustainable growth, competitiveness, security and integration of Russian regions.

Noted that the axiological factors cover all components of the mental regional space, including "regional cultural capital», "regional culture», "regional identity» and «regional brand». «Cultural capital» includes a set of moral, spiritual and cultural characteristics of the region's population, formed in the context of "regional culture», which reflects the basics of the state regional policy, defines the regional value system, ways and nature of life of a particular territory. In its turn, «regional identity» is the result of the formation of self-consciousness of the regional community as an independent and original entity, on the one hand, and as part of a holistic state system, on the other. The embodiment of identification processes at the regional level is the "regional brand», which serves as a public indicator of the cultural regional space, expresses and satisfies regional interests and values.

Shown that the axiological factors can be implemented in the form of a humanoriented paradigm of regional development, which suggests inclusive models and high socio-economic regional indicators. Substantiated the relevance of the person-oriented approach both in the modern theoretical and methodological research, and in the formation of the regulatory framework for regional development. In particular, the features of the human-oriented paradigm are reflected in the Concept of long-term socio-economic development of the Russian Federation until 2020, in the Basics of the state policy of regional development of the Russian Federation until 2025, as well as in the Strategy of the state cultural policy until 2030.

Keywords: regional development; axiological factors; regional cultural capital; regional culture; regional identity; regional brand; human-oriented paradigm; Russia.

\footnotetext{
Korovnikova Natalia Alexandrovna - Candidate of Political Sciences, Senior Researcher of the Department of Economics, Institute of Scientific Information on Social Sciences of the Russian Academy of Sciences (INION RAN), Associate Professor of the Department of Economics and Management, Moscow Institute of Economics, Politics and Law (MIEPL), Moscow. E-mail: natalia.kor@list.ru
} 
Масштабные изменения советской административно-территориальной системы послужили причиной существенных деформаций регионального устройства России. На протяжении последних трех десятилетий региональная политика оказалась под влиянием кардинально противоположных центробежных («парад суверенитетов») и центростремительных (централизация власти, укрепление федеральной составляющей) тенденций. Очевидно, что поиск и достижение наиболее оптимальных пропорций регионального развития зависит от своевременной реализации «Основ государственной политики регионального развития Российской Федерации на период до 2025 года» [Основы государственной политики 2017], обусловливающих не только состояние локальных и региональных образований, но и экономическое развитие, национальную безопасность, единство и территориальную целостность всего государства.

Сегодня приоритетные задачи регионального развития заключаются в обеспечении высоких темпов экономического роста и конкурентоспособности на основе интеграции, эффективного взаимодействия и сотрудничества регионов России. Принимая во внимание «многообразие региональных условий, разницу ресурсных потенциалов, уникальные черты исторического развития, специфику социокультурного ландшафта, образующих нашу страну территорий» [Луковников 2013, с. 42], скорейшее решение этих задач зависит как от материально-технических и социальных условий, так и от аксиологических факторов регионального развития. Последнее включают все ментальные сегменты региона: мировоззренческий (региональный менталитет), информационно-психологический, социально-политический (идеологический) и, конечно, культурологический.

Причем характер и особенности развития регионов в таком полисоставном государстве как Россия обусловлены определенным набором рациональных и иррациональных характеристик. Их можно разделить на объективные, естественно-геополитические (природно-климатические условия, человеческие ресурсы, геополитическое положение и территория, историческое наследие, цивилизационные характеристики и т.п.) и субъективные - результат государственной и региональной политики (система стандартизированных показателей, в том числе ВВП на душу населения, доходы населения, уровень безработицы, состояние рынка труда, демографические показатели, инвестиционный климат, туризм, комфортность проживания и инфраструктуры, социально-экономический, политический, электоральный фон, репутационный капитал, представления о регионе в общественном сознании и т.п.) [Нагорняк 2013].

Комплексность и устойчивость развития регионов в рамках общенационального хозяйства предполагает «рациональное использование природноресурсного потенциала региона; пропорциональное сочетание различных 
отраслей; формирование устойчивых внутрирегиональных и межрегиональных производственных и технологических связей; а также наличие особого сообщества людей с определенными традищиями, ценностями и образом жизни» [Шабунова, Груздева 2016, с. 101]. Другими словами, в структуру региона как социальной системы помимо экономической, социальной, политико-правовой, экологической входит и аксиологическая подсистема, охватывающая его ментальное культурное пространство или пространство ценностей [Касаткин 2017, с. 151].

Сегодня приобретает актуальность вопрос о взаимосвязи между ценностями, с одной стороны, и экономическими, социальными, политическими и технологическими изменениями в регионах - с другой. Механизм их взаимодействия до конца не выяснен, но наиболее целостной представляется позиция, согласно которой региональные особенности следует рассматривать как результат изменения аксиологических аспектов, а преобразования структуры региональных ценностей считать причиной общественных сдвигов, учитывая, что эти влияния взаимны [Плотникова, Германов 2016, с. 71].

Аксиологические факторы подразумевают состояние и потенциал культурного капитала региона. Культурный капитал включает в себя региональную культуру, региональную идентичность и региональный бренд, а также их реализацию в форме человекоориентированной парадигмы регионального развития.

В широком смысле культурный капитал региона аккумулирует следующие разновидности: воплощенный (умения и навыки), объективированный (символическое воплощение), институционализированный («свидетельства ценности») (П. Бурдье), а также acnекты: материальный и духовный (Д. Тросби). Культурный капитал - это «богатство в виде знаний и умений, которые сформированы данной территорией у жителей и от которых в дальнейшем будет зависеть ее поступательное развитие» [Шабунова, Гулин, Окулова, Соловьёва 2009, с. 58]. Он воплощается «в уровне образованности населения, в деятельности учреждений культуры, в морально-нравственных ценностях, в уровне здоровья населения, в его социальных связях, в информированности, в досуговом времяпрепровождении, в предпринимательской и научной активности, в навыках и способностях, в мотивации и целесообразном применении усилий, наконец, способности к инновационной деятельности» [Шабунова, Гулин, Окулова, Соловьёва 2009, с. 58].

Региональный культурный капитал формируется на базе двух взаимосвязанных и взаимодополняющих начал - «культуры региона» $u$ «региональной культуры». В первом случае речь идет о локально (пространственно) закрепленной культуре, отражающей общестрановые ценности; она отличается «только особенностями бытового уклада и характером повседневности» [Мурзина 2003, с. 8]. Второй случай - «вариант общенациональной культуры 174 
и одновременно самостоятельное явление, обладающее собственными закономерностями развития и логикой исторического существования» [Мурзина 2003 , с. 8]. Это специфическая форма организации и функционирования локального социума. Она «опирается на историческую традицию, формирует систему ценностей» и «особый тип личности», существует «внутри национальной (“материнской”) культуры и наряду с ней» [Мурзина 2003, с. 11].

Региональная культура «отражает ... весь комплекс общественных взаимоотношений, коммуникации общества и власти, взгляды и представления регионального населения на общественно-политическое развитие как своего региона, так и всего государства» [Еремина 2011 б, с. 70]; объясняет механизмы коммуникации между обществом и социальными институтами; определяет вектор государственной интеграции или дезинтеграции (интеграционной региональной политики, подразумевающей компромиссный характер взаимодействий в системе «регион-центр» и / или дезинтеграционной региональной политики, указывающей на конфликтный характер взаимоотношений между центром и регионом, на стремление регионального образования отстаивать собственные локальные интересы в качестве приоритетных [Еремина 2011 б, с. 77]). Региональная культура - один из важнейших факторов коллективной мобилизации и развития государственности.

Региональная культура порождает особую форму коллективной идентичности - региональную идентичность, которая находит свое выражение в «духе региона» и является результатом регионального самосознания [Мурзина 2003, с. 11-12]. Оно предполагает понимание целей и мотивов регионального развития, а также самовосприятие регионального сообщества как самостоятельного субъекта и как части государственной и геополитической систем.

Региональная идентичность представляет собой сложную многокомпонентную структуру, которую в общих терминах можно определить «как результат когнитивного, ценностного, эмоционального процессов осознания принадлежности индивида к своему региональному сообществу, проявляющихся в созидательной деятельности на благо своего региона, укреплении его места и роли в системе территориальных общностей, формировании имиджа региона» [Еремина 2011 a]. Комплексный анализ идентичности регионов современной России требует применения различных подходов: соџиологического (изучение соотношения общенационального и регионального в разных регионах); политологического (особенности регионального политического процесса); культурологического (характер современного культурогенеза в российских регионах); электорально-географического (обнаружение ценностных политико-идеологических различий между регионами) [Шабалова 2014, с. 144]. 
Региональная идентичность как аксиологический фактор регионального развития является результатом двух взаимодополняющих процессов: интеграции и дифференциации. Результатом идентификационных процессов в рамках регионального пространства может быть как негативная форма региональной идентичности, которая предполагает различные проявления регионального аксиологического нигилизма, отрицания своей региональной принадлежности, так и позитивная региональная идентичность, для которой характерны положительная оценка субъектом своей социально-территориальной и культурно-региональной позиции; сохранение аутентичности территории; ее адаптация к новым региональным и глобальным тенденциям развития.

В научной среде ведутся многочисленные дискуссии относительно разграничения понятий «бренд», «имидж», «образ», «стереотип» [Чепкасов 2016]. Многие отечественные исследователи полагают, что свое символическое выражение региональная идентичность находит в форме регионального бренда, который представляет собой совокупный результат региональных идентификационных процессов и «олицетворяет отношение жителей территории к себе (к своим возможностям, пониманию своего успеха и комфорта, защищенности и значимости, удовлетворенности и перспектив)» [Нагорняк 2013]. Этот бренд служит публичными индикатором культурного пространства региона, выражает социальные ценности и удовлетворяет социальные интересы, обеспечивает преемственность, инновационность и конкурентоспособность регионального развития и т.п. [Нагорняк 2013].

Региональная политика по продвижению бренда региона - очень перспективное направление, позволяющее «совершенствовать социокультурную атмосферу в регионе, а именно приобщать население к участию в социальной жизни, создавать условия для развития творческого потенциала жителей, разрабатывать проекты по изменению внешнего облика регионов с целью позитивного отношения граждан к региону и конкретному месту» [Игнатова, Туранина 2016, с. 87-88]. Все это позволяет не только повысить статус региона во внешнем страновом и геополитическом пространстве, но и сформировать благоприятную среду внутрирегиональной коммуникации.

На современном этапе перехода к обществу знаний интеллектуальный и культурный капитал становятся императивом общественного развития, обусловливая содержание основных экономических категорий [Курушина, Дружинина 2016, с. 24]. Особую важность приобретают основы поведенческой экономики, которая учитывает особенности человеческих отношений, когнитивные ограничения (ограниченная рациональность), эмоциональные факторы (различные проявления эмпатии и альтруизма) [Peña, Mejía, Villano 2016, c. 7].

В связи с этим на первый план выходит человекоориентированная парадигма региона-социума [Курушина, Дружинина 2016, с. 24], в рамках которой 
конкурентоспособность регионального сообщества рассматривается через призму трех элементов аксиологически-ориентированного развития, именно: 1) экономического (реальная заработная плата, качество жизни, экспорт на душу населения); 2) социоприродного (уровень долголетия, криминогенность, возможности коммуникации, социальная и транспортная связанность регионального пространства) и 3) инклюзивного развития (социальная защищенность, развитие инновационной среды) [Курушина, Дружинина 2016, с. 40].

Человекоориентированный подход применяется не только в рамках современных теоретико-методологических исследований, но также используется для разработки нормативно-правовой базы регионального развития. Так, в Концепции долгосрочного социально-экономического развития России в числе приоритетных целевых ориентиров отмечены высокие стандарты благосостояния человека, социальное благополучие и согласие, сбалансированное пространственное развитие [Концепция 2008]. Повышение качества жизни определяется как одна из основных целей государственной политики регионального развития Российской Федерации на период до 2025 г. [Основы государственной политики 2017]. Согласно Стратегии государственной культурной политики на период до 2030 г., социально-экономическая модернизация страны невозможна без инвестиций в человека, которые позволяют предотвратить снижение интеллектуального и культурного уровня общества, деформацию исторической памяти, искажение ценностных ориентиров и размывание традиционных российских духовно-нравственных ценностей [Стратегия 2016].

Таким образом, особое внимание к аксиологическим факторам регионального развития, формирование на их основе человекоориентированной политики будет способствовать консолидации материальных и духовных ресурсов не только на уровне регионального сообщества, но и на общегражданском, государственном макроуровне.

\section{Библиография}

Еремина Е.В. Региональная идентичность в контексте социологического анализа // Регионология. Саранск, 2011 а. № 3. URL: https://regionsar.ru/ru/node/781 (Дата обращения: 16.05.2019.)

Еремина Н.В. Региональная политическая культура как фактор государственного развития: интеграция versus дезинтеграция // Вестник СПбГУ. Сер. 6. 2011 б. Вып. 3. С. 70-78. URL: https://cyberleninka.ru/article/n/regionalnaya-politicheskaya-kultura-kak-faktor-gosudarstven-nogorazvitiya-integratsiya-versus-dezintegratsiya (Дата обращения: 16.05.2019.)

Игнатова И.Б., Туранина Н.А., Колесникова И.Г., Сергеева А.Ю. Бренд региона и его составляющие (на материале «Белгород - город добра и благополучия») // Наука. Искусство. Культура. Белгород, 2016. № 3 (11). С. 82-88. URL: https://cyberleninka.ru/article/n/brendregiona-i-ego-sostavlyayuschie-na-materiale-belgorod-gorod-dobra-i-blagopoluchiya (Дата обращения: 16.05.2019.) 


\section{РАЗМЫШЛЕНИЯ, СООБЩЕНИЯ, КОММЕНТАРИИ}

Касаткин П.И. Культурное пространство: аксиологический аспект // Знание. Понимание. Умение. 2017. № 4. C. 145-156. URL: http://journals.mosgu.ru/zpu/article/view/586 (Дата обращения: 16.05.2019.)

Концепция долгосрочного социально-экономического развития Российской Федерации на период до 2020 года (Распоряжение Правительства Российской Федерации № 1662-р от 17 ноября 2008 г.) // Правительство России: Официальный сайт. URL: http:/government.ru/info/ 6217/ (Дата обращения: 16.05.2019.)

Курушина Е.В. Человекоориентированная система управления развитием территорий на региональном и муниципальном уровнях // Российские регионы в фокусе перемен. XI Международная конференция. Екатеринбург: Издательство УМЦ УПИ, 2016. Ч. 1. С. 150-159.

Курушина Е.В., Дружинина И.В. Человекоориентированное развитие российских регионов. Тюмень: ТИУ, 2016. 158 c. URL: http://elib.tyuiu.ru/wp-content/uploads/2017/04/16543.pdf (Дата обращения: 16.05.2019.)

Луковников Е.В. Региональное развитие в системе приоритетов государственной политики современной России // Власть. 2013. № 7. С. 42-45. URL: http://jour.isras.ru/upload/journals/ 2/articles/1726/submission/original/1726-3296-1-SM.pdf (Дата обращения: 16.05.2019.)

Мурзина И.Я. Феномен региональной культуры: бытие и самосознание. Автореф. дис. ... д-ра культурол. наук: 24.00.01. Екатеринбург: Изд-во Урал. пед. ун-та, 2003. 47 с. URL: http://elar.urfu.ru/bitstream/10995/417/1/urgu0199s.pdf (Дата обращения: 16.05.2019.)

Нагорняк Т.Л. Брендинг территории как вектор политики // Знание. Понимание. Умение. 2013. № 4. URL: http://www.zpu-journal.ru/e-zpu/2013/4/Nagornyak_Place-Branding/ (Дата обращения: 16.05.2019.)

Натхов Т.В., Полищук Л.И. Политэкономия институтов и развития: как важно быть инклюзивным. Доклад. М.: Институт экономики РAH, 2017. 55 c. URL: https://inecon.org/docs/ Natkhov_Polishuk_paper_20170221.pdf (Дата обращения: 16.05.2019.)

Основы государственной политики регионального развития Российской Федерации на период до 2025 года (Указ Президента Российской Федерации № 13 от 16 января 2017 г.) // Президент России: Официальный сайт. URL: http://static.kremlin.ru/media/acts/files/000120170 1160039.pdf (Дата обращения: 16.05.2019.)

Плотникова Е.В., Германов И.А., Борисова Н.В. Структура ценностей населения и модернизационный статус регионов России // Философские науки. 2016. № 4. C. 70-79. URL: http://www.phisci.ru/files/issues/previews/RJPS-04-2016 Preview.pdf (Дата обращения: 16.05.2019.)

Стратегия государственной культурной политики на период до 2030 года (Распоряжение Правительства Российской Федерации № 326-р от 29 февраля 2016 г.) // Правительство России: Официальный сайт. URL: http://static.government.ru/media/files/AsA9RAyYVAJnoBuKgH0qEJ A9IxP7f2xm.pdf (Дата обращения: 16.05.2019.)

Чепкасов А.В. Образ - имидж - стереотип региона (к определению понятий) // Вестник Новосибирского государственного университета. Сер.: История, филология. 2016. Т. 15. № 6. C. 139-145. URL: https://cyberleninka.ru/article/n/obraz-imidzh-stereotip-regiona-k-opredeleniyuponyatiy (Дата обращения: 16.05.2019.)

Шабалова О.А. Формирование подходов к изучению феномена «региональная идентичность» в российском дискурсе // Magister Dixit. Научно-педагогический журнал Восточной Сибири. Иркутск, 2014. № 2. С. 139-145. URL: https://cyberleninka.ru/article/n/formirovaniepodhodov-k-izucheniyu-fenomena-regionalnaya-identichnost-v-rossiyskom-diskurse (Дата обращения: 16.05.2019.)

Шабунова А.А., Груздева М.А. Развитие регионов Российской Федерации: интегральная методика как инструмент оценки // Региональная экономика: теория и практика. 2016. № 1 . 
C. 100-112. URL: https://cyberleninka.ru/article/n/razvitie-regionov-rossiyskoy-federatsii-integralnaya-metodika-kak-instrument-otsenki (Дата обращения: 16.05.2019.)

Шабунова А.А., Гулин К.А., Окулова Н.А., Соловьёва Т.С. Социокультурные аспекты развития территории. Вологда: ИСЭРТ РАН, 2009. $131 \mathrm{c.}$ URL: http://library.vscc.ac.ru/ Files/books/12997390591666V.PDF (Дата обращения: 16.05.2019.)

Peña V., Mejía A.G., Villano X.G. El rol de la ética y de la percepción de riesgo en las decisiones de inversion // Documento de Trabajo FCEA. 2016. N 23. 24 p. URL: http://www. javerianacali.edu.co/sites/ujc/files/node/field-documents/field_document_file/ddtn232016.pdf (Дата обращения: 16.05.2019.)

\section{References}

Chepkasov A.V. Obraz - imidzh - stereotip regiona (k opredeleniju ponjatij). Vestnik Novosibirskogo gosudarstvennogo universiteta. Ser.: Istorija, filologija. 2016. T. 15. No 6. P. 139-145. URL: https://cyberleninka.ru/article/n/obraz-imidzh-stereotip-regiona-k-opredeleniyu-ponyatiy (Date of access: 16.05.2019.)

Eremina E.V. Regional'naja identichnost' v kontekste sociologicheskogo analiza. Regionologija. Saransk, 2011 a. No 3. URL: https://regionsar.ru/ru/node/781 (Date of access: 16.05.2019.)

Eremina N.V. Regional'naja politicheskaja kul'tura kak faktor gosudarstvennogo razvitija: integracija versus dezintegracija. Vestnik SPbGU. Ser. 6. 2011 b. Iss. 3. P. 70-78. URL: https:// cyberleninka.ru/article/n/regionalnaya-politicheskaya-kultura-kak-faktor-gosudarstvennogo-razvitiyaintegratsiya-versus-dezintegratsiya (Date of access: 16.05.2019.)

Ignatova I.B., Turanina N.A., Kolesnikova I.G., Sergeeva A.Ju. Brend regiona i ego sostavljajushhie (na materiale «Belgorod - gorod dobra i blagopoluchija»). Nauka. Iskusstvo. Kul'tura. Belgorod, 2016. No 3 (11). P. 82-88. URL: https://cyberleninka.ru/article/n/brend-regiona-i-egosostavlyayuschie-na-materiale-belgorod-gorod-dobra-i-blagopoluchiya (Date of access: 16.05.2019.)

Kasatkin P.I. Kul'turnoe prostranstvo: aksiologicheskij aspect. Znanie. Ponimanie. Umenie. 2017. No 4. P. 145-156. URL: http://journals.mosgu.ru/zpu/article/view/586 (Date of access: 16.05.2019.)

Koncepcija dolgosrochnogo social'no-jekonomicheskogo razvitija Rossijskoj Federacii na period do 2020 goda (Rasporjazhenie Pravitel'stva Rossijskoj Federacii No 1662-r ot 17 nojabrja 2008 g.) Pravitel'stvo Rossii: Official Website. URL: http://government.ru/info/6217/ (Date of access: 16.05.2019.)

Kurushina E.V. Chelovekoorientirovannaja sistema upravlenija razvitiem territorij na regional'nom i municipal'nom urovnjah. Rossijskie regiony $\mathrm{v}$ fokuse peremen. XI Mezhdunarodnaja konferencija. Ekaterinburg: Izdatel'stvo UMC UPI, 2016. Ch. 1. P. 150-159.

Kurushina E.V., Druzhinina I.V. Chelovekoorientirovannoe razvitie rossijskih regionov. Tjumen': TIU, 2016. 158 p. URL: http://elib.tyuiu.ru/wp-content/uploads/2017/04/16543.pdf (Date of access: 16.05.2019.)

Lukovnikov E.V. Regional'noe razvitie v sisteme prioritetov gosudarstvennoj politiki sovremennoj Rossii. Vlast'. 2013. No 7. P. 42-45. URL: http://jour.isras.ru/upload/journals/2/ articles/1726/submission/original/1726-3296-1-SM.pdf (Date of access: 16.05.2019.)

Murzina I.Ja. Fenomen regional'noj kul'tury: bytie i samosoznanie. Avtoref. dis. ... d-ra kul'turol. nauk: 24.00.01. Ekaterinburg: Izd-vo Ural. ped. un-ta, 2003. 47 p. URL: http://elar.urfu.ru/ bitstream/10995/417/1/urgu0199s.pdf (Date of access: 16.05.2019.)

Nagornjak T.L. Brending territorii kak vektor politiki // Znanie. Ponimanie. Umenie. 2013. No 4. URL: http://www.zpu-journal.ru/e-zpu/2013/4/Nagornyak_Place-Branding/ (Date of access: 16.05.2019.) 


\section{РАЗМЫШЛЕНИЯ, СООБЩЕНИЯ, КОММЕНТАРИИ}

Nathov T.V., Polishhuk L.I. Politjekonomija institutov i razvitija: kak vazhno byt' inkljuzivnym. Doklad. M.: Institut jekonomiki RAN, 2017. 55 p. URL: https://inecon.org/docs/Natkhov_Polishuk_ paper_20170221.pdf (Date of access: 16.05.2019.)

Osnovy gosudarstvennoj politiki regional'nogo razvitija Rossijskoj Federacii na period do 2025 goda (Ukaz Prezidenta Rossijskoj Federacii No 13 ot 16 janvarja 2017 g.) Prezident Rossii: Official Website. URL: http://static.kremlin.ru/media/acts/files/0001201701160039.pdf (Date of access: 16.05 .2019 .)

Peña V., Mejía A.G., Villano X.G. El rol de la ética y de la percepción de riesgo en las decisiones de inversion. Documento de Trabajo FCEA. 2016. No 23. 24 p. URL: http://www. javerianacali.edu.co/sites/ujc/files/node/field-documents/field_document_file/ddtn232016.pdf (Date of access: 16.05.2019.)

Plotnikova E.V., Germanov I.A., Borisova N.V. Struktura cennostej naselenija i modernizacionnyj status regionov Rossii. Filosofskie nauki. 2016. No 4. P. 70-79. URL: http://www.phisci.ru/ files/issues/previews/RJPS-04-2016_Preview.pdf (Date of access: 16.05.2019.)

Shabalova O.A. Formirovanie podhodov k izucheniju fenomena «regional'naja identichnost'»v rossijskom diskurse. Magister Dixit. Nauchno-pedagogicheskij zhurnal Vostochnoj Sibiri. Irkutsk, 2014. No 2. P. 139-145. URL: https://cyberleninka.ru/article/n/formirovanie-podhodov-k-izucheniyufenomena-regionalnaya-identichnost-v-rossiyskom-diskurse (Date of access: 16.05.2019.)

Shabunova A.A., Gruzdeva M.A. Razvitie regionov Rossijskoj Federacii: integral'naja metodika kak instrument ocenki. Regional'naja jekonomika: teorija i praktika. 2016. No 1. P. 100-112. URL: https://cyberleninka.ru/article/n/razvitie-regionov-rossiyskoy-federatsii-integralnaya-metodika-kakinstrument-otsenki (Date of access: 16.05.2019.)

Shabunova A.A., Gulin K.A., Okulova N.A., Solov'eva T.S. Sociokul'turnye aspekty razvitija territorii. Vologda: ISJeRT RAN, 2009. 131 p. URL: http://library.vscc.ac.ru/Files/books/1299739 0591666V.PDF (Date of access: 16.05.2019.)

Strategija gosudarstvennoj kul'turnoj politiki na period do 2030 goda (Rasporjazhenie Pravitel'stva Rossijskoj Federacii No 326-r ot 29 fevralja 2016 g.) Pravitel'stvo Rossii: Official Website. URL: http://static.government.ru/media/files/AsA9RAyYVAJnoBuKgH0qEJA9IxP7f2xm. pdf (Date of access: 16.05.2019.) 